\title{
EVALUATE HEALTH-RELATED QUALITY OF LIFE AMONG URBAN ELDERS IN DIFFERENT LIVING ENVIRONMENTS
}

\author{
H. Xing ${ }^{1}$, W. Yu ${ }^{2}$, S. Chen ${ }^{1}$, Y. Sun ${ }^{1}$, X. He $e^{1}$
}

\begin{abstract}
Background: This study aimed to assess and compare the health-related quality of life (HRQOL) in older people who lived with different living mode, including staying at home with spouse or child, staying at home alone and staying in nursing home. Methods: Data were collected by cross-sectional survey in 2013. The sample included 95 elderly people who were staying at home with spouse or child, 43 elderly people at home alone and 93 elderly people in nursing home. Results: The three groups were similar according to gender, education and existence of chronic disease. The univariate analysis showed that physical component summary (PCS) and mental component summary (MCS) scores of HRQOL were lower in those living in nursing home than those living in their own homes. The scores of PCS and MCS for the old elderly people (over 75 years old) were lower compared to the young elderly people (60-74 years old). The scores of PCS and MCS for elderly people who had part or incapacity of self-care ability were lower compared to complete self-care ability. There was a positive correlation between the number of weekly physical exercise and PCS and MCS. The main influential factors for PCS were physical exercise, age and self-care ability, physical exercise also affected MCS based on multiple linear regression analysis. Conclusion: These data suggest that PCS and MCS are not lower in elderly assisted living in nursing home compared to staying at home by multiple statistical analyses. HRQOL may be affected by physical exercise.
\end{abstract}

Key words: Health-related quality of life, elderly, residential environments, China.

\section{Introduction}

Health-related quality of life (HRQOL) has been increasingly used in the medical area, from clinical trials and clinical practice to observational studies, and health surveys (1-3). HRQOL is an indicator of disease severity, a lower HRQOL is associated with greater mortality among elderly people with disease, such as coronary disease, heart failure, pulmonary disease and osteoarthritis (4-7). As to elderly people from the general population, HRQOL is also a good indicator of health status (8).

Population aging has become a common concern for social issues around the world. The number of elderly people who were 60 years old and above was more than 202 million in 2013, about accounting for 14.9 percent of the total population in China, based on the 2013 statistical bulletin of social service development (9). China's elderly population will reach 248 million, about $17 \%$ in 2020. In

1. Dept. of Nursing, School of Medicine-Shaoxing University, Zhejiang Province, China; 2. Institute of Epidemiology, Shaoxing Keqiao District Center for Disease Control and Prevention, Zhejiang Province, China

Corresponding Author: Haiyan Xing, Dept. of Nursing, School of MedicineShaoxing University, Zhejiang Province, China, Tel: +86-575-88346871 Email: petrelx99@163.com

2050 the severe aging stage will be coming, which the number will reach 437 million, accounting for more than $30 \%$ of the Chinese population (10). Shaoxing city located in eastern China, the number of elderly people was more than 857 thousand, accounting for $19.7 \%$ of the city's population in 2012 (11).

Traditionally, most of elderly people relied on their children to live, whether or not having own pension. Recently the mode of life of elderly people changed slowly because of economic development and related policy implement. One-child family policy was introduced in 1979 in China, the "4:2:1" phenomenon which means that couples are solely responsible for the care of one child and four parents has become general family structure in urban after 35 years. The burden of family is too heavy to take good care of elderly, so more and more elderly people tend to live in nursing home.

In this study, the aim was to assess and compare HRQOL in elderly people with different living mode, including staying at home with spouse or child, at home alone and in nursing home.

\section{Materials and Methods}

This cross-sectional study was carried out from July to August 2013 in Shaoxing city of China. The study 
included participants who were at least 60 years old. One social welfare center or nursing home was surveyed and two communities were drawn up based on simple random sampling. The study population consisted of two groups. The first group consisted of 138 elders living in their private homes (95 elders staying with spouse or child, 43 elders alone). The other group in this study consisted of 93 elderly people living in social welfare center. The center, which is only one in the city, is a public social establishment. Elderly population can live in the health center as long as the cost is paid.

\section{Measure of quality of life}

Health-related quality of life was assessed using the SF-36 questionnaire (12). The SF-36 questionnaire is a generic instrument with scores that are based on responses to individual questions (13). It is made up of 36 items that measure the following 8 health dimensions or scales: physical functioning (PF); role-physical (RP); bodily pain (BP); general health $(\mathrm{GH})$; vitality $(\mathrm{VT})$; social functioning (SF); role-emotional (RE) and mental health $(\mathrm{MH})$. On each scale, missing values can be imputed in cases where at least half the constituent items are available. Each scale has a score of $0-100$, such that the higher the score indicates the better the HRQOL (8). In addition, the scores of the eight subscales were computed into two summary scores, physical component summary (PCS) and mental component summary score (MCS) (13). The scale has been confirmed to have good reliability and validity and is appropriate for the Chinese elderly population (14).

\section{Statistical analysis}

Statistical analyses were performed using SPSS version 18.0 software. The statistical method included the chi-square test, independent-samples t-test, one way ANOVA, and multiple linear regressions.

\section{Results}

Data were obtained from 231 older urban adults in Shaoxing. Their sociodemographic characteristics are shown in Table 1. No significant differences in gender, education and chronic disease were found among different living mode. The age of elders staying in nursing home was older than at home $(\mathrm{P}<0.001)$. According to a physician's report, $66.7 \%$ of the elderly people had a chronic disease.

There were no significant difference in perceived physical and mental health between gender, education and presence of chronic disease. However, the scores of PCS and MCS for the old elderly people (over 75 years old) were lower compared to the young elderly people (60-74 years old). PCS and MCS for elderly people who had part or incapacity of self-care ability were lower compared to complete self-care ability. There was a positive correlation between the number of weekly physical exercise and PCS and MCS. PCS and MCS for those living in nursing home were lower compared to those living at home ( $\mathrm{P}<0.01$ for each comparison). The mean scores of PCS and MCS of elderly population were reported in Table 2.

The main influential factors for PCS were physical exercise, age and self-care ability. Physical exercise also affected MCS. HRQOL was positively influenced by physical exercise in PCS and MCS. PCS were also closely negatively related to the age factor. PCS for those having part or incapacity of self-care ability was lower to those having complete self-care ability (Table 3 ).

\section{Discussion}

The SF-36 has generally been used for patients and general people (15-18). Some studies used the SF-36 in ordinary of healthy elderly people to assess quality of life. The SF-36 scale (Chinese version) has been confirmed to be appropriate for the Chinese population $(19,20)$. The

Table 1

Properties of older adults in different living environments

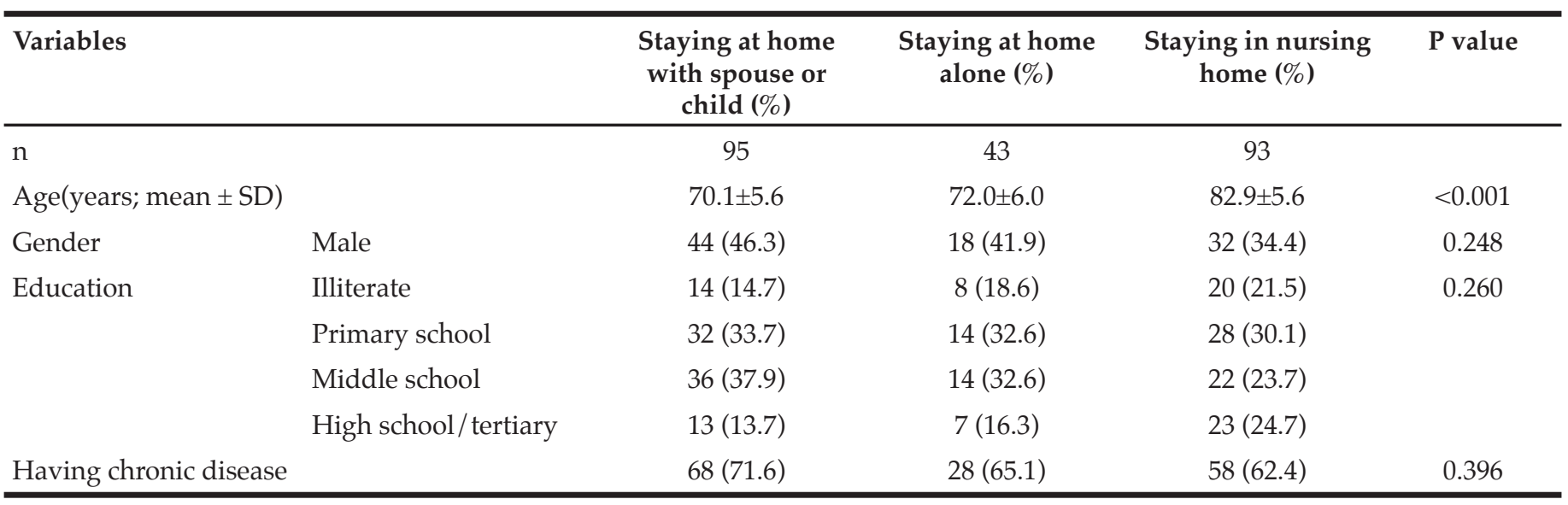


Table 2

The distribution of scores to SF-36 according to different variables (mean \pm standard deviation)

\begin{tabular}{|c|c|c|c|c|c|}
\hline Variables & & \multicolumn{2}{|c|}{ PCS } & \multicolumn{2}{|c|}{ MCS } \\
\hline Overall & & $68.8 \pm 20.0$ & - & $74.5 \pm 14.8$ & - \\
\hline \multirow[t]{2}{*}{ Age } & $60-74$ years & $77.3 \pm 15.4$ & $<0.001$ & $77.8 \pm 13.1$ & 0.001 \\
\hline & $75+$ years & $61.1 \pm 20.6$ & & $71.4 \pm 15.6$ & \\
\hline \multirow[t]{4}{*}{ Education } & Illiterate & $69.9 \pm 16.6$ & 0.076 & $73.6 \pm 12.4$ & 0.613 \\
\hline & Primary school & $67.2 \pm 22.4$ & & $73.0 \pm 15.0$ & \\
\hline & Middle school & $73.1 \pm 17.3$ & & $75.6 \pm 15.4$ & \\
\hline & High school/tertiary & $63.4 \pm 21.9$ & & $76.2 \pm 15.5$ & \\
\hline \multirow[t]{2}{*}{ Self-care ability } & Complete & $75.3 \pm 16.5$ & $<0.001$ & $77.4 \pm 14.4$ & $<0.001$ \\
\hline & Part or incapacity & $56.6 \pm 20.3$ & & $69.2 \pm 13.9$ & \\
\hline \multirow{3}{*}{$\begin{array}{l}\text { Number of weekly physical } \\
\text { exercise }\end{array}$} & $<1$ & $52.1 \pm 20.8$ & $<0.001$ & $66.9 \pm 15.7$ & 0.001 \\
\hline & $1-2$ & $69.7 \pm 13.5$ & & $73.2 \pm 11.5$ & \\
\hline & $\geq 3$ & $72.8 \pm 19.2$ & & $76.8 \pm 14.7$ & \\
\hline \multirow[t]{2}{*}{ Living environments } & $\begin{array}{l}\text { Staying at home with } \\
\text { spouse or child }\end{array}$ & $75.8 \pm 17.0$ & $<0.001$ & $78.1 \pm 13.6$ & 0.001 \\
\hline & Staying at home alone & $74.3 \pm 17.5$ & & $75.9 \pm 13.2$ & \\
\hline
\end{tabular}

scale has good reliability and validity in measuring the HRQOL of elderly people in China (14).

In this study, the mean age of elders who are staying in nursing home is higher than those who are staying in their own homes (Table 1), the majority of urban elders staying in nursing home were the old elderly people $(94.6 \%)$. It is possible that the young elderly people are often more healthy and the incidence of chronic disease is lower, so self-care are easier than for the old elderly people. In Shanghai, the characteristics of the aged in nursing home were more of the old elderly people, females, the widowed, illiterates or primarily educated, diseased, and disabled (21).

Our results based on both univariate and multivariate analyses indicated that the PCS and MCS were related with physical exercise. There was a positive correlation between HRQOL and the number of weekly physical exercise (Table 2, 3). So it showed that regular exercise was not only good for physical health but also beneficial for mental health. Physical activity could reduce the risks of many diseases, and decrease health burdens for both healthy people and patients with chronic diseases. Both men and women with recommended levels of physical activity had a lower risk of cardiovascular diseases, ischemic stroke, diabetes mellitus, and osteoporosis $(22,23)$. Periodical physical exercise could also improve mood, thereby reduced the incidence of anxiety and depression (24).The amount of physical activity or meeting physical activity recommended levels had positive effects on HRQOL for the general population $(23,25)$. So the elderly people should promote physical exercise to improve their HRQOL. PCS were also related with self-care ability and age (Table3), which were similar to previous studies $(26,27)$.

Though univariate analysis showed that the PCS and MCS were both related living environment, there was no significant difference based on multivariate statistical analysis. The PCS and MCS for those living in nursing home were not lower compared to those living at home (Table 2, 3). Similar study indicated that the score of PF, $\mathrm{RP}, \mathrm{BP}, \mathrm{GH}, \mathrm{VT}, \mathrm{SF}$ of elderly people for those living in nursing home were lower compared to those living at home by one-way ANOVA, however the results of multivariate analysis were not mentioned (28).

Under the Chinese traditional conception, the elderly people who lived in nursing home were no children 
Table 3

Variables associated with HRQOL, revealed by multiple linear regression

\begin{tabular}{|c|c|c|c|c|c|c|}
\hline \multirow[t]{2}{*}{ Variable } & \multicolumn{3}{|c|}{ PCS } & \multicolumn{3}{|c|}{ MCS } \\
\hline & $\beta$ & Beta & P value & $\beta$ & Beta & P value \\
\hline Constant & 118.080 & & & 97.713 & & \\
\hline Age & -0.659 & -0.274 & 0.001 & -0.315 & -0.178 & 0.054 \\
\hline \multicolumn{7}{|c|}{ Number of weekly physical exercise $($ control $=<1$ ) } \\
\hline $1-2$ & 16.513 & 0.320 & $<0.001$ & 5.748 & 0.151 & 0.067 \\
\hline$\geq 3$ & 18.917 & 0.452 & $<0.001$ & 9.086 & 0.294 & $<0.001$ \\
\hline Self-care ability & -10.474 & -0.250 & $<0.001$ & -4.024 & -0.130 & 0.095 \\
\hline \multicolumn{7}{|c|}{ Living environments (control=staying at home with spouse or child) } \\
\hline Staying at home alone & 0.624 & 0.012 & 0.831 & -1.292 & -0.035 & 0.612 \\
\hline Staying in nursing home & -2.453 & -0.060 & 0.498 & -1.887 & -0.062 & 0.552 \\
\hline
\end{tabular}

and spouse, and environments and quality of services were not good. Elders had no choices but staying in nursing home. Now this situation was changing. Our results showed that most elderly people were pleased among 93 urban elderly people who stayed in nursing home. About $96.8 \%$ elderly people were satisfied for environment and facility, and $93.5 \%$ were satisfied for quality served by nursing home. This result was similar to another research which $93.2 \%$ of the aged was satisfied in nursing home (29). When elderly people were asked that whether they like the living mode at present, the percent of saying yes was $89.5 \%, 58.1 \%$, and $91.4 \%$ in who staying at home with spouse or child, at home alone and in nursing home respectively. If they could re-choose the living mode, the percent was $40.8 \%, 14.3 \%$ and $44.8 \%$ respectively. Compare to the previous, the environment and quality of nursing home have great improvement with economic development. In Shaoxing social welfare center, the staff consists of doctors, nurses, care workers, particularly nursing workers. The center divides into three blocks, including self-care area, referral assistance area and specially protected areas. In self-care area, where healthy elderly live in, the daily diet is provided. In assistant district, where frail elderly live in, diet and medical care is available. In specially protected areas, where bedridden elderly live in, all-weather hand care is provided. Residents have opportunities to read, draw, watch TV, play chess, participate in physical exercise and so on. There are also table tennis room, billiards room, fitness room, physical room, painting room, kinds of sports facilities, outdoor gate stadium, bocce court, supermarket, restaurant and so on. Comprehensive physical and mental health care and rehabilitation are available for those elderly people who need.

With the number of elderly people increasing quickly, the way of living in nursing home will be more and more popular and become the main way of life among elderly people in near future. The contradiction between nursing home without sufficient beds and the demand of the aged will become increasingly prominent. So our government and some social organizations should build and improve more pension institutions to adapt to rapid development of the aging process.

\section{Limitations}

The subjects were recruited from the elderly people in one district in China, where is only one social welfare center. So the district-specific bias may have influenced the results and the present findings cannot be generalized to all elders. Influential factors of HRQOL are too many to include all factors in this study, other factors such as social support, economic level and sudden positive or negative events were not mentioned in this research. It is also difficult to determine a causal relationship in a crosssectional study.

\section{Conclusions}

The univariate analysis results indicate that the scores of PCS and MCS for elderly people who live in nursing home are lower than those people who stay at home. However multivariate statistical analysis results show that quality of life be no significant difference among different living environments. The main influential factors for PCS are number of weekly physical exercise, age and self-care ability. Physical exercise also affects MCS of elderly people. Regular physical exercise is one effective way to improve HRQOL of elderly people.

Ethical Consideration: Ethical issues (such as informed consent, co-authorship, misconduct, conflict of interest, plagiarism, double submission, etc) have been considered carefully by the authors.

Acknowledgments: This study was supported by grants from Home Theoretical Research Policy Planning Issues of Zhejiang Province (ZMYB201416). 
Conflict of Interest: None

\section{References}

1. Valderas, JM., Kotzeva, A., Espallargues M., Guyatt G.,Ferrans CE., Halyard MY. Revicki DA, Symonds T, Parada A, Alonso J. The impact of measuring patient-reported outcomes in clinical practice: A systematic review of the literature. Qual Life Res, 2008;17(2), 179-93.

2. Fryback DG., Dunham NC, Palta M., Hanmer J, Buechner J, Cherepanov D, Herrington SA, Hays RD, Kaplan RM, Ganiats TG, Feeny D, Kind P. US norms for six generic health-related quality-of-life indexes from the National Health Measurement study. Medical Care, 2007;45(12), 1162-70.

3. Palacio-Vieira JA, Villalonga-Olives E, Valderas JM, Espallargues M, Herdman M, Berra S, Alonso J, Rajmil L. Changes in health-related quality of life (HRQoL) in a population-based sample of children and adolescentsafter 3 years of follow-up, Qual Life Res, 2008;17:1207-15

4. Rumsfeld JS, MaWhinney S, McCarthy M Jr, Shroyer AL, VillaNueva CB, O'Brien M, Moritz TE, Henderson WG, Grover FL, Sethi GK, Hammermeister KE. Health-related quality of life as a predictor of mortality following coronary artery bypass graft surgery. Participants of the department of veterans affairs cooperative study group on processes, structures, and outcomes of care in cardiac surgery. JAMA, 1999;281(14), 1298-303

5. Rodriguez-Artalejo F, Guallar-Castillon P, Pascual CR, Otero CM, Montes AO, Garcia AN, Conthe P, Chiva MO, Banegas JR, Herrera MC. Health related quality of life as a predictor of hospital readmission and death among patients with heart failure. Arch Intern Med, 2005;165(11), 1274-9

6. Domingo-Salvany A, Lamarca R, Ferrer M, Garcia-Aymerich J, Alonso J, Félez M, Khalaf A, Marrades RM, Monsó E, Serra-Batlles J, Antó JM. Healthrelated quality of life and mortality in male patients with chronic obstructive pulmonary disease. Am J Respir Crit Care Med, 2002;166(5), 680-5

7. Singh JA, Nelson DB, Fink HA, Nichol KL. Health-related quality of life predicts future health care utilization and mortality in veterans with selfreported physician-diagnosed arthritis: The veterans arthritis quality of life study. Semin Arthritis Rheu, 2005;34(5), 755-65

8. Otero-Rodríguez A, Leo'n-Muñz LM, Balboa-Castillo T, Banegas JR, Rodríguez-Artalejo F, Guallar-Castillo'n P). Change in health-related quality of life as a predictor of mortality in the older adults. Qual Life Res, 2010;19:15-23

9. http://www.mca.gov.cn/article/zwgk/mzyw/201406/20140600654488. shtml; accessed June 17,2014

10. http:/ / news.qq.com/a / 20091026/001890.htm; accessed October 26, 2009

11. http:// roll.sohu.com/20130219/n366446375.shtml; accessed February 19, 2013

12. Ware JE, Snow KK, Kosinski M, Gandet B. SF-36 Health survey manual and interpretation guide. The Health Institute, New England Medical Center, Boston, 1993

13. Zheng Y, Ye DQ, Pan HF, Li WX, Li LH, Li J, Li XP, Xu JH. Influence of social support on health-related quality of life in patients with systemic lupus erythematosus. Clin Rheumatol, 2009;28:265-9
14. Zhou B, Chen K, Wang JF, Wu YY, Zheng WJ, Wang H. Reliability and validity of a Short Form Health Survey Scale(SF-36)-Chinese version used in an elderly population of Zhejiang province in China. Chin J Epidemiol, 2008;29(12):1193-8

15. Ingels JB, Corso PS. The impact of violence on African-American teenagers' health-related quality of life, as measured by the SF-36, Inj. Prev., 2012;18: A143.

16. Chushkin M, Maliev B, Belevskiy A, Meshcheryakova N, Bukhareva S, Smerdin S. Using SF-36 in assessment of quality of life in patients cured of pulmonary tuberculosis, Eur Respir J, 2011;38: 2591.

17. Ou YY, Pan XX, Wang ZH, Shen PY, Wang WM, Ren H, Zhang W, Chen N Surveying quality of life in patients with Fabry disease by the SF-36 scale, Chin J Nephrol, 2014;30(3):201-205

18. Zhou B, Chen K, Yu YX, Wang H, Wang JF (2010). Quality of life among the elderly hypertensive population in two areas of Zhejiang province, Chin J Epidemiol, 2010;31(4):474-5

19. Li L, Wang HM, Shen Y. Development and psychometric tests of a Chinese version of the SF-36 Health Survey Scales, Chin J Prev Med, 2002;36(2):109-13

20. Yan Z, Pen AH, Liu FF, Zhang LR, Li XH. Effect evaluation on the quality of life in rural migrant workers by SF-36 scale, Modern Preventive Medicine, 2010;37(10):1900-1, 4

21. Tang JK, Li HY, You JK, Chen LL, Zhao NQ. Countermeasures and suggestion for improving the Life Quality of old people in nursing homes. Chinese General Practice. 2009;12(1A):31-3

22. U.S. Department of Health and Human Services. Physical Activity and Health: A Report of the Surgeon General. Atlanta, GA: U.S. Department of Health and Human Services, Center for Disease Control and Prevention, National Center for Chronic Disease Prevention and Health Promotion, 1996.

23. Morimoto T, Oguma Y, Yamazaki S, Sokejima S, Nakayama T, Fukuhara S. Gender differences in effects of physical activity on quality of life and resource utilization, Qual Life Res, 2006;(15): 537-46

24. Cioffi J, Schmied V, Dahlen H, Mills A, Thornton C, Duff M, Cummings J, Kolt G.S. Physical Activity in Pregnancy: Women's Perceptions, Practices, and Influencing Factors. J Midwifery Womens Health, 2010;55(5):455-61

25. Vuillemin A, Boini S, Bertrais S, Tessier S, Oppert JM, Hercberg S, Guillemin F, Briançon S. Leisure time physical activity and health-related quality of life, Prev Med. 2005;41(2):562-9.

26. Wang WJ, Liu L, Jiang QC. Application of EQ-5D and SF-12 scales in assessment of the quality of life in patients with diabetes in rural areas in Anhui Province. Chin J Dis Controf Prev. 2013;17(4):287-90

27. Fu Q, Xie JP. Life quality and its influencing factors among the elderly in Shenzhen city. Chin J Public Health. 2010;26(8):1026-7

28. Yin YQ, Long LL, Xia LH. Influence of diferent endowment patterns on Quality of Life of elderly in rural areas. Occup and Health. 2014;30(6):812-4

29. Han WB, Sun FX. Survey on satisfaction of elderly people in Nicheng community nursing home in Shanghai. Shanghm Journal of Preventive Medicine. 2014;26(4):203-4 